\title{
Entropy generation by nanofluid with variable thermal conductivity and viscosity in a flat plate solar collector
}

\author{
Rehena Nasrin* and M. A. Alim \\ Department of Mathematics, Bangladesh University of Engineering and Technology, Dhaka - 1000, BANGLADESH \\ *Corresponding Author: e-mail: raity11@ gmail.com
}

\begin{abstract}
The entropy generation by nanofluid with variable thermal conductivity and viscosity of assisted convective flow across a riser pipe of a horizontal flat plate solar collector is investigated numerically. The water based nanofluid with copper nanoparticles is used as the working fluid inside the fluid passing riser pipe. The governing partial differential equations with proper boundary conditions are solved by Finite Element Method using Galerkin's weighted residual scheme with discretization by triangular mesh elements having six nodes. The effects of temperature dependent thermal conductivity and viscosity related to performance such as temperature, velocity and heat flux distributions, heat transfer rate, mean temperature and velocity, collector efficiency and mid-height temperature (dimensional), mean entropy generation and Bejan number of the nanofluid as well as base fluid are investigated systematically. The results show that the better performance of heat transfer through the collector is found by using the higher and lower values of variable thermal conductivity and viscosity respectively. Thermal efficiency improves about $8 \%$ using water/Cu nanofluid. Numerical result obtained from present study is validated with the result available in the literature.
\end{abstract}

Keywords: Entropy generation, assisted convection, nanofluid, finite element method, variable thermal conductivity and viscosity.

\section{Introduction}

The fluids with solid-sized nanoparticles suspended in them are called "nanofluids". The natural convection in enclosures continues to be a very active area of research during the past few decades. Due to small sizes and very large specific surface areas of the nanoparticles, nanofluids have superior properties like high thermal conductivity, minimal clogging in flow passages, longterm stability, and homogeneity. Applications of nanoparticles in thermal field are to enhance heat transfer from solar collectors to storage tanks, to improve efficiency of coolants in transformers. Thermal conductivity and viscosity are very important properties in nanofluid heat transfer mechanism. Thermal conductivity and viscosity of fluids are temperature dependent.

Elbashbeshy (2000) and Rahman et al. (2008) investigated the effects of temperature dependent thermal conductivity and viscosity. Hwang et al. (2007) studied the stability and thermal conductivity characteristics of nanofluids. In this study, they concluded that the thermal conductivity of ethylene glycol was increased by 30\%. Parvin et al. (2012) analyzed thermal conductivity variation of water-alumina nanofluid in an annulus where two thermal conductivity models namely were used to evaluate the heat transfer enhancement in the annulus. Roslan et al. (2011) investigated heat transfer in a naonofluid filled trapezoidal enclosure with variable thermal conductivity and viscosity. They found that the effect of the viscosity was more dominant than the thermal conductivity. Effects of variable viscosity and thermal conductivity of CuO-water nanofluid on heat transfer enhancement was analyzed by Abu-Nada (2009) and Molla et al. (2012). Measurement of temperature-dependent thermal conductivity and viscosity of $\mathrm{TiO}_{2}$-water nanofluids was conducted by Duangthongsuk and Wongwises (2009). Their result 
showed that thermal conductivity of nanofluids increased with increasing nanofluid temperatures and conversely the viscosity of nanofluids decreased with increasing temperature of nanofluids.

Conduction convection radiation processes of a solar collector using FEA was performed by Moningi (2008), Álvarez et al. (2010). Tripanagnostopoulos et al. (2000) investigated solar collectors with colored absorbers. Amrutkar et al. (2012), Dara et al. (2013) studied passive flat plate solar collector. Karanth et al. (2011) performed numerical simulation of a solar flat plate collector using discrete transfer radiation model (DTRM)-a CFD Approach. Dynamics (CFD) by employing conjugate heat transfer showed that the heat transfer simulation due to solar irradiation to the fluid medium, increased with an increase in the mass flow rate.

Natarajan and Sathish (2009) studied role of nanofluids in solar water heater. The aim of their paper was to analyze and compare the heat transfer properties of the nanofluids with the conventional fluids. Enhancement of flat-plate solar collector thermal performance with silver nano-fluid was conducted by Polvongsri and Kiatsiriroat (2011). With higher thermal conductivity of the working fluid the solar collector performance could be enhanced compared with that of water. Piao et al. (1994) studied forced convective heat transfer in cross-corrugated solar air heaters. Li et al. (2011), Taylor et al. (2011), Otanicar et al. (2009, 2010) investigated nanofluid flow heat transfer through solar collector.

Struckmann (2008) prepared a project report on flat-plate solar collector where efforts had been made to combine a number of the most important factors into a single equation and thus formulate a mathematical model. Kalogirou (2004) gave a survey report based on solar thermal collectors and applications. Martín et al. (2011), Zambolin (2011), Sandhu (2013), Karuppa et al. (2012) theoretically and experimentally performed solar thermal collector systems and components.

All thermofluidic processes involve irreversibilities and therefore incur an efficiency loss. In practice, the extent of these irreversibilities can be measured by the entropy generation rate. In designing practical systems, it is desirable to minimize the rate of entropy generation so as to maximize the available energy Hooman et al. (2008), Shahi et al. (2011), Delavar and Hedayatpour (2012), Khorasanizadeh et al. (2013), Mahian et al. (2014), Parvin et al. (2014) and Nasrin et al. (2014).

From the literature review it is mentioned that a very few numerical works have been done introducing temperature dependent thermal conductivity and viscosity properties of nanofluid. In spite of that there is a large scope to work with nanofluid flow and heat transfer by analyzing these two properties. In this paper, the effects of variable thermal conductivity and viscosity of nanofluid through a flat plate solar collector are investigated numerically. So, the objective of this article is to present the improvement of thermal efficiency using water/Cu nanofluid due to the thermal conductivity and viscosity variation.

\section{Physical Modeling}

A longitudinal cross section of the system considered in the present study is shown in Figure 1. The system consists of a flat plate solar collector. The numerical computation is carried on taking single riser pipe of FPSC. The glass cover is at the top of the FPSC. It is highly transparent and anti-reflected (called the glazing). The glass top surface is exposed to solar irradiation. It is made up of borosilicate which has thermal conductivity of $1.14 \mathrm{~W} / \mathrm{mK}$ and refractive index of 1.47 , specific heat of $750 \mathrm{~J} / \mathrm{kgK}$ and coefficient of sunlight transmission of $95 \%$. The wavelength of visible light is roughly $700 \mathrm{~nm}$. Thickness of glass cover is $0.005 \mathrm{~m}$. There is an air gap of $0.005 \mathrm{~m}$ between glass cover and absorber plate. Air density $=1.269 \mathrm{Kg} / \mathrm{m}^{3}$, specific heat $=287.058$ $\mathrm{J} / \mathrm{kgK}$ and thermal conductivity $=0.0243 \mathrm{~W} / \mathrm{mK}$. All these properties of air domain represent air of temperature at $298 \mathrm{~K}$. A dark colored copper absorber plate is under the air gap. Length, width and thickness of the absorber plate are $1 \mathrm{~m}, 0.15 \mathrm{~m}$ and $0.0005 \mathrm{~m}$ respectively. Coefficients of heat absorption and emmision of copper absorber plate are $95 \%$ and $5 \%$ respectively. The riser pipe has inner diameter $0.01 \mathrm{~m}$ and thickness $0.0005 \mathrm{~m}$. The riser tube is also made in copper metal.

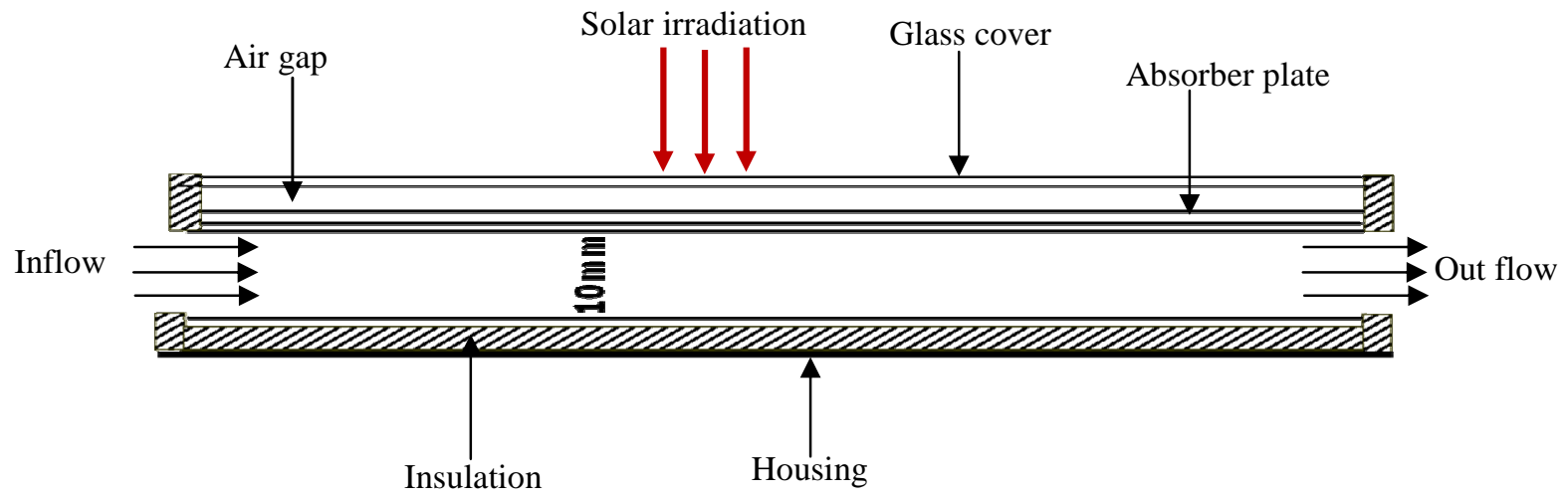

Figure 1: Longitudinal cross-section of a FPSC

The working fluid in the collector is water-based nanofluid containing $\mathrm{Cu}$ nanoparticles. The nanoparticles are generally spherical shaped and diameter is taken as $5 \mathrm{~nm}$. The nanofluid is considered as single phase flow and surfactant analysis is 
neglected. $A, L$ and $H$ are the surface area, length and height of the collector. In the present problem, it can be considered that the flow is considered to be laminar and there is no viscous dissipation. The nanofluid is assumed incompressible. It is taken that water and nanoparticles are in thermal equilibrium and no slip occurs between them. The density of the nanofluid is approximated by the Boussinesq model. Only steady state case is considered.

The computation domain is a fluid passing copper riser pipe which is attached ultrasonically to the absorber plate. The fluid enters from the left inlet and getting heat from solid boundaries and finally exits from the right outlet of the riser pipe of a flat plate solar collector. The incident radiation is considered to be the incoming solar radiation. For the study of the principal behavior of the nanofluid based FPSC, atmospheric absorption is neglected in this calculation. Once the intensity distributions are evaluated, the energy balance on the solar collector is performed and the temperature profile within it is obtained. In order to carry out these steps, some assumptions are made.

\subsection{Mathematical Modeling}

Let $I$ be the intensity of solar radiation and $A$ be any surface area, then the amount of energy received by any surface is:

$Q_{i}=I . A$

This equation is modified for solar collector surface as it is the product of the rate of transmission of the cover $(\tau)$ and the absorption rate of the absorber $(\alpha)$. Thus,

$$
Q_{\text {recv }}=I(\tau \alpha) A
$$

Then the temperature of absorber becomes higher than that of the surrounding. Some heat is lost to the atmosphere by convection and radiation. The rate of heat loss $\left(Q_{\text {loss }}\right)$ depends on the collector overall heat transfer coefficient $\left(U_{l}\right)$ and the collector temperature.

$$
Q_{\text {loss }}=U_{l} A\left(T_{c o l}-T_{a m b}\right)
$$

The rate of useful energy extracted by the collector $\left(Q_{u s f}\right)$ is:

$$
Q_{u s f l}=Q_{\text {recv }}-Q_{\text {loss }}=I(\tau \alpha) \quad A-U_{l} A\left(T_{c o l}-T_{\text {amb }}\right)
$$

It is also known that the rate of extraction of heat from the collector may be measured by means of the amount of heat carried away in the fluid passed through it. Thus

$$
Q_{\text {usfl }}=m C_{p}\left(T_{\text {out }}-T_{\text {in }}\right)
$$

where $m, C_{p}, T_{\text {in }}$ and $T_{\text {out }}$ are the mass flow rate per unit area, the specific heat at constant pressure, inlet and outlet fluid temperatures respectively.

Equation (4) may be inconvenient because of the difficulty in defining the collector average temperature. It is convenient to define a quantity that relates the actual useful energy gain of a collector to the useful gain if the whole collector surface were at the fluid inlet temperature. This quantity is known as "the collector heat removal factor $\left(F_{R}\right)$ " and is expressed as:

$$
F_{R}==\frac{m C_{p}\left(T_{\text {out }}-T_{\text {in }}\right)}{A\left[I(\tau \alpha)-U_{l}\left(T_{\text {in }}-T_{\text {amb }}\right)\right]}
$$

The maximum possible useful energy gain in a solar collector occurs when the whole collector is at the inlet fluid temperature. The actual useful energy gain $\left(Q_{u s f l}\right)$, is found by multiplying the collector heat removal factor $\left(F_{R}\right)$ by the maximum possible useful energy gain. This allows the rewriting of equation (4):

$$
Q_{u s f l}=F_{R} A\left[I(\tau \alpha)-U_{l}\left(T_{i n}-T_{a m b}\right)\right]
$$

Equation (7) is a widely used relationship for measuring collector energy gain and is generally known as the "Hottel-WhillierBliss equation".

The heat flux per unit area for the geometry having single riser pipe is $\frac{q^{\prime}}{N}=q=I \tau \alpha-U_{l}\left(T_{i n}-T_{a m b}\right)$ where $N$ is number of riser pipe and $T_{a m b}$ is ambient temperature outside the collector.

A measure of a flat plate collector performance is the collector efficiency $(\eta)$ defined as the ratio of the useful energy gain $\left(Q_{u s f}\right)$ to the incident solar energy. The instantaneous thermal efficiency of the collector is: 


$$
\eta=\frac{Q_{\mathrm{usfl}}}{A I}=\frac{F_{R} A\left[I(\tau \alpha)-U_{l}\left(T_{i n}-T_{a m b}\right)\right]}{A I}=F_{R}(\tau \alpha)-F_{R} U_{l} \frac{\left(T_{i n}-T_{a m b}\right)}{I}
$$

The 2D governing equations for laminar forced convection through a solar collector filled with water/copper nanofluid in terms of the Navier-Stokes and energy equation (dimensional form) are given as:

Continuity equation:

$$
\frac{\partial u}{\partial x}+\frac{\partial v}{\partial y}=0
$$

$x$-momentum equation:

$\rho_{n f}\left(u \frac{\partial u}{\partial x}+v \frac{\partial u}{\partial y}\right)=-\frac{\partial p}{\partial x}+\left[\frac{\partial}{\partial x}\left(\mu_{n f} \frac{\partial u}{\partial x}\right)+\frac{\partial}{\partial y}\left(\mu_{n f} \frac{\partial u}{\partial y}\right)\right]$

y-momentum equation:

$\rho_{n f}\left(u \frac{\partial v}{\partial x}+v \frac{\partial v}{\partial y}\right)=-\frac{\partial p}{\partial y}+\left[\frac{\partial}{\partial x}\left(\mu_{n f} \frac{\partial v}{\partial x}\right)+\frac{\partial}{\partial y}\left(\mu_{n f} \frac{\partial v}{\partial y}\right)\right]$

Energy equation for fluid:

$u \frac{\partial T}{\partial x}+v \frac{\partial T}{\partial y}=\frac{1}{\left(\rho C_{p}\right)_{n f}}\left[\frac{\partial}{\partial x}\left(k_{n f} \frac{\partial T}{\partial x}\right)+\frac{\partial}{\partial y}\left(k_{n f} \frac{\partial T}{\partial y}\right)\right]$

Energy equation for absorber:

$$
\left(\frac{\partial^{2} T_{a}}{\partial x^{2}}+\frac{\partial^{2} T_{a}}{\partial y^{2}}\right)=0
$$

where, $\rho_{n f}=(1-\phi) \rho_{f}+\phi \rho_{s}$ is the density,

$\left(\rho C_{p}\right)_{n f}=(1-\phi)\left(\rho C_{p}\right)_{f}+\phi\left(\rho C_{p}\right)_{s}$ is the heat capacitance,

In the current study, the viscosity of the nanofluid is considered by the Brinkman model (1952)

$$
\mu_{n f}=\mu_{f}(1+\phi)^{-2.5}
$$

The thermal conductivity of Maxwell Garnett (MG) model (1904) is

$$
k_{n f}=k_{f} \frac{k_{s}+2 k_{f}-2 \phi\left(k_{f}-k_{s}\right)}{k_{s}+2 k_{f}+\phi\left(k_{f}-k_{s}\right)}
$$

There are very few forms of viscosity variation available in the literature. Among them one is considered here which is appropriate for liquid introduced by Hossain et al. (2000) as follows:

$$
\mu=\mu_{\infty}\left[1+\chi\left(T-T_{i n}\right)\right]=\left(\text { say } \mu_{n f}\right)
$$

where $\mu_{\infty}$ be the viscosity of the ambient fluid and $\chi=\frac{1}{\mu}\left(\frac{\partial \mu}{\partial T}\right)$ be a constant evaluated at the film temperature of the flow $T_{f l}=\frac{1}{2}\left(T_{a m b}+T_{i n}\right)$.

Consider the temperature dependent thermal conductivity, which is proposed by Charraudeau (1975), as follows

$$
k=k_{\infty}\left[1+\delta\left(T-T_{\text {in }}\right)\right]=\left(\text { say } k_{n f}\right)
$$


where $k_{\infty}$ is the thermal conductivity of the ambient fluid and $\delta$ is defined as $\delta=\frac{1}{\kappa}\left(\frac{\partial \kappa}{\partial T}\right)$.

The boundary conditions are:

at all solid boundaries: $u=v=0$

at the solid-fluid interface: $k_{n f}\left(\frac{\partial T}{\partial y}\right)_{n f}=k_{\text {solid }}\left(\frac{\partial T_{a}}{\partial y}\right)_{\text {solid }}$

at the inlet boundary: $T=T_{i n}, u=u_{\text {in }}$

at the outlet boundary: convective boundary condition $p=0$

at the top surface of absorber: heat flux $-k_{a} \frac{\partial T_{a}}{\partial y}=q=I \tau \alpha-U_{l}\left(T_{i n}-T_{a m b}\right)$

at outer surface of riser pipe: $\frac{\partial T}{\partial y}=0$

The above equations are non-dimensionalized by using the following dimensionless dependent and independent variables:

$$
X=\frac{x}{L}, Y=\frac{y}{L}, U=\frac{u}{U_{\text {in }}}, V=\frac{v}{U_{\text {in }}}, P=\frac{p}{\rho_{f} U_{\text {in }}^{2}}, \theta=\frac{\left(T-T_{\text {in }}\right) k_{f}}{q L}, \theta_{a}=\frac{\left(T_{a}-T_{i n}\right) k_{a}}{q L}
$$

Then the non-dimensional governing equations are

$$
\frac{\partial U}{\partial X}+\frac{\partial V}{\partial Y}=0
$$

$U \frac{\partial U}{\partial X}+V \frac{\partial U}{\partial Y}=-\frac{\rho_{f}}{\rho_{n f}} \frac{\partial P}{\partial X}+\frac{(1+\varepsilon \theta)}{\operatorname{Re} \rho_{n f}}\left(\frac{\partial^{2} U}{\partial X^{2}}+\frac{\partial^{2} U}{\partial Y^{2}}\right)+\frac{\varepsilon}{\operatorname{Re} \rho_{n f}}\left(\frac{\partial \theta}{\partial X} \frac{\partial U}{\partial X}+\frac{\partial \theta}{\partial Y} \frac{\partial U}{\partial Y}\right)$

$U \frac{\partial V}{\partial X}+V \frac{\partial V}{\partial Y}=-\frac{\rho_{f}}{\rho_{n f}} \frac{\partial P}{\partial Y}+\frac{(1+\varepsilon \theta)}{\operatorname{Re} \rho_{n f}}\left(\frac{\partial^{2} V}{\partial X^{2}}+\frac{\partial^{2} V}{\partial Y^{2}}\right)+\frac{\varepsilon}{\operatorname{Re} \rho_{n f}}\left(\frac{\partial \theta}{\partial X} \frac{\partial V}{\partial X}+\frac{\partial \theta}{\partial Y} \frac{\partial V}{\partial Y}\right)$

$U \frac{\partial \theta}{\partial x}+V \frac{\partial \theta}{\partial y}=\frac{1}{\operatorname{RePr}} \frac{1}{\alpha_{f}\left(\rho C_{p}\right)_{n f}}\left[(1+\gamma \theta)\left(\frac{\partial^{2} \theta}{\partial X^{2}}+\frac{\partial^{2} \theta}{\partial Y^{2}}\right)+\gamma\left\{\left(\frac{\partial \theta}{\partial X}\right)^{2}+\left(\frac{\partial \theta}{\partial Y}\right)^{2}\right\}\right]$

$\left(\frac{\partial^{2} \theta_{a}}{\partial X^{2}}+\frac{\partial^{2} \theta_{a}}{\partial Y^{2}}\right)=0$

where $\operatorname{Pr}=\frac{v_{f}}{\alpha_{f}}$ be the Prandtl number, $\operatorname{Re}=\frac{U_{\text {in }} L}{v_{f}}$ be the Reynolds number, $\gamma=\delta\left(T_{i n}-T_{a m b}\right)$ and $\varepsilon=\chi\left(T_{i n}-T_{a m b}\right)$ be the dimensionless thermal conductivity and viscosity variation parameter.

The corresponding boundary conditions take the following form:

at all solid boundaries: $U=V=0$

at the solid-fluid interface: $k_{n f}\left(\frac{\partial \theta}{\partial Y}\right)_{n f}=k_{\text {solid }}\left(\frac{\partial \theta_{a}}{\partial Y}\right)_{\text {solid }}$

at the inlet boundary: $\theta=0, U=1$

at the outlet boundary: convective boundary condition $P=0$

at the top surface of absorber: heat flux $\frac{\partial \theta_{a}}{\partial Y}=-\frac{k_{f}}{k_{n f}}$

at outer surface of riser pipe: $\frac{\partial T}{\partial y}=0$ 


\subsection{Average Nusselt number}

The average Nusselt number $(\mathrm{Nu})$ is expected to depend on a number of factors such as thermal conductivity, heat capacitance, viscosity, flow structure of nanofluids and volume fraction, dimensions and fractal distributions of nanoparticles. Equation of local Nusselt number for flow through the absorber tube of solar collector can be written as

$$
N u=\frac{U_{l} L}{k_{f}}=\frac{Q}{\Delta T}\left(\frac{L}{k_{f}}\right)=\frac{Q}{\left(q L / k_{f}\right)}\left(\frac{L}{k_{f}}\right)
$$

where $L$ is the length of riser pipe, $\Delta T$ is the difference between riser pipe surface temperature and ambient temperature, $Q$ is the energy received or lost by the absorber pipe surface. For a flat plate solar collector constant heat flux is assigned at the absorber top surface. For water based nanofluid flow this equation becomes

$$
N u=\frac{-k_{n f}\left(\frac{\partial T}{\partial y}\right)}{\left(q L / k_{f}\right)}\left(\frac{L}{k_{f}}\right)=-\left(\frac{k_{n f}}{k_{f}}\right)\left(\frac{k_{f}}{q}\right)\left(\frac{\partial T}{\partial y}\right)
$$

The non-dimensional form of local convective heat transfer at the top surface of riser pipe is

$$
N u=-\frac{k_{n f}}{k_{f}} \frac{\partial \theta}{\partial Y}
$$

By integrating the local Nusselt number over the top heated surface, the average convective heat transfer along the heated wall of the collector is used as $\overline{N u}=\int_{0}^{1} N u d X$.

\subsection{Mean bulk temperature and velocity}

The mean bulk temperature and average sub domain velocity of the fluid inside the collector may be written as

$\theta_{a v}=\int \theta d \bar{V} / \bar{V}$ and $\mathrm{V}_{a v}=\int \mathrm{V} d \bar{V} / \bar{V}$, where $\bar{V}$ is the volume of the riser pipe.

\subsection{Entropy Generation}

The entropy generation in the flow field is caused by the non-equilibrium flow imposed by boundary conditions. In the convection process, the entropy generation is due to the irreversibility caused by the heat transfer phenomena and fluid flow friction. According to Bejan $(1979,1982,1996)$, the dimensional local entropy generation, $s_{\text {gen }}$, can be expressed by:

$$
s_{g e n}=\frac{k_{n f}}{T_{a m b}^{2}}\left[\left(\frac{\partial T}{\partial x}\right)^{2}+\left(\frac{\partial T}{\partial y}\right)^{2}\right]+\frac{\mu_{n f}}{T_{a m b}}\left[2\left(\frac{\partial u}{\partial x}\right)^{2}+2\left(\frac{\partial v}{\partial y}\right)^{2}+\left(\frac{\partial u}{\partial x}+\frac{\partial v}{\partial y}\right)^{2}\right]
$$

In equation (23), the first term represents the dimensional entropy generation due to heat transfer $\left(s_{\text {gen,h }}\right)$, while the second term represents the dimensional entropy generation due to viscous dissipation $\left(s_{\text {gen,v }}\right)$. By using dimensionless parameters, the expression of the non-dimensional entropy generation, $S_{g e n}$ can be written by:

$$
\begin{aligned}
& S_{g e n}=s_{g e n} \frac{T_{a m b} L^{2}}{k_{f}\left(T_{c o l}-T_{i n}\right)^{2}} \\
& =\frac{k_{n f}}{k_{f}}\left[\left(\frac{\partial \theta}{\partial X}\right)^{2}+\left(\frac{\partial \theta}{\partial Y}\right)^{2}\right]+\chi \frac{\mu_{n f}}{\mu_{f}}\left[2\left(\frac{\partial U}{\partial X}\right)^{2}+2\left(\frac{\partial V}{\partial Y}\right)^{2}+\left(\frac{\partial U}{\partial X}+\frac{\partial V}{\partial Y}\right)^{2}\right] \\
& =S_{g e n, h}+S_{g e n, v}
\end{aligned}
$$

Here $S_{\text {gen, } h}$ and $S_{g e n, v}$ are the dimensionless entropy generation for heat transfer and viscous effect respectively. In Eq. (24), $\chi$ is the irreversibility factor which represents the ratio of the viscous entropy generation to thermal entropy generation. It is given as:

$$
\chi=\frac{T_{a m b} \mu_{f}}{k_{f}} \frac{U_{i}^{2}}{\left(T_{c o l}-T_{i n}\right)^{2}}
$$


The dimensionless average entropy generation, $S$ for the entire computational domain is as follows:

$$
S=\frac{1}{\bar{V}} \int S_{g e n} d \bar{V}=S_{g e n, h, m}+S_{g e n, v, m}
$$

where $S_{g e n, h, m}$ and $S_{g e n, v, m}$ are the average entropy generation for heat transfer and viscous effect respectively.

The Bejan number, $B e$, defined as the ratio between the entropy generation due to heat transfer by the total entropy generation, is expressed as

$$
B e=\frac{S_{g e n, h, m}}{S}
$$

It is known that the heat transfer irreversibility is dominant when $B e$ approaches to 1 . When $B e$ becomes much smaller than $1 / 2$ the irreversibility due to the viscous effects dominates the processes and if $B e=1 / 2$ the entropy generation due to the viscous effects and the heat transfer effects are equal Khorasanizadeh (2013).

\section{Numerical Computation}

The Galerkin FEM method of Taylor and Hood (1973), Zienkiewicz (1991) and Dechaumphai (1999) is used to solve the nondimensional governing equations along with boundary conditions for the considered problem. Conservation equations are solved for the finite element method to yield the velocity and temperature fields for the water flow in the absorber tube and the temperature field for the absorber plate. The equation of continuity has been used as a constraint due to mass conservation and this restriction may be used to find the pressure distribution. Then the velocity components $(U, V)$ and temperatures $\left(\theta, \theta_{a}\right)$ of governing equations (18-22) are expanded using a basis set. The Galerkin finite element technique yields the subsequent nonlinear residual equations. Gaussian quadrature technique is used to evaluate the integrals in these equations. The non-linear residual equations are solved using Newton-Raphson method to determine the coefficients of the expansions. The convergence of solutions is assumed when the relative error for each variable between consecutive iterations is recorded below the convergence criterion such that $\left|\psi^{n+1}-\psi^{n}\right| \leq 1.0 \mathrm{e}^{-6}$, where $n$ is the number of iteration and $\Psi$ is a function of $U, V, \theta$ and $\theta_{a}$.

\subsection{Mesh Generation}

In the finite element method, the mesh generation is the technique to subdivide a domain into a set of sub-domains, called finite elements, control volume, etc. The discrete locations are defined by the numerical grid, at which the variables are to be calculated. It is basically a discrete representation of the geometric domain on which the problem is to be solved. Figure 2 displays the finite element mesh of the present physical domain. The length and width of the computational domain are $1 \mathrm{~m}$ and $0.0115 \mathrm{~m}$ respectively. The computational domains with irregular geometries by a collection of finite elements make the method a valuable practical tool for the solution of boundary value problems arising in various fields of engineering.

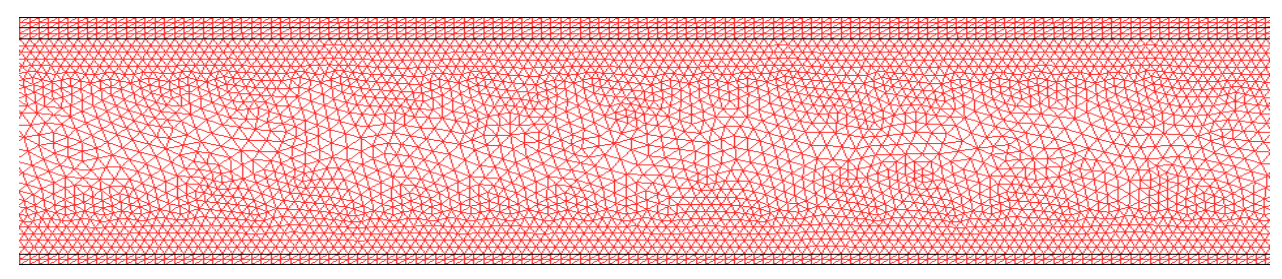

Figure 2: Mesh generation of the FPSC

\subsection{Grid Refinement Test}

An extensive mesh testing procedure is conducted to guarantee a grid-independent solution for $\operatorname{Pr}=5.8, \phi=2 \%, I=215 \mathrm{~W} / \mathrm{m}^{2}$ and $R e=480$ through a riser pipe of a FPSC. In the present work, four different non-uniform grid systems are examined with the number of elements within the resolution field: 42,010, 99,832, 1,50,472, 1,68,040 and 1,90,519. The numerical scheme is carried out for highly precise key in the average Nusselt number for water-copper nanofluid $(\phi=2 \%)$ as well as base fluid $(\phi=0 \%)$ for the aforesaid elements to develop an understanding of the grid fineness as shown in Table 1. From the fourth and fifth column in the Table 1 it is observed that there is no significant change in the rate of heat transfer but time consuming. So considering the non-uniform grid system of 1,68,040 elements is preferred for the computation. This element size is taken from extra fine meshing. 
Table 1: Grid test at $\operatorname{Pr}=5.8, \phi=2 \%, I=215 \mathrm{~W} / \mathrm{m}^{2}$ and $R e=480$

\begin{tabular}{|c|c|c|c|c|c|}
\hline Elements & 42,010 & 99,832 & $1,50,472$ & $1,68,040$ & $1,90,519$ \\
\hline$N u$ (nanofluid) & 7.82945 & 9.19176 & 10.17518 & 10.84991 & 10.85001 \\
\hline$N u$ (basefluid) & 6.62945 & 7.99976 & 8.88701 & 9.551698 & 9.551718 \\
\hline Time (s) & 126.265 & 312.594 & 398.157 & 481.328 & 929.377 \\
\hline
\end{tabular}

\subsection{Thermo-physical Properties}

The thermo-physical properties of the water and nanoparticles are taken from Nasrin et al. (2014) and given in Table 2.

Table 2: Thermo physical properties of fluid and nanoparticles

\begin{tabular}{ccc}
\hline Physical Properties & Fluid phase (Water) & $\mathrm{Cu}$ \\
\hline$C_{p}(\mathrm{~J} / \mathrm{kgK})$ & 4179 & 385 \\
$\rho\left(\mathrm{kg} / \mathrm{m}^{3}\right)$ & 997 & 8933 \\
$k\left(\mathrm{~W} / \mathrm{mK}^{2}\right.$ & 0.613 & 400 \\
$\alpha \times 10^{7}\left(\mathrm{~m}^{2} / \mathrm{s}\right)$ & 1.47 & 1163.1 \\
\hline
\end{tabular}

\subsection{Code Validation}

The present results are verified against the existing results available in the literature.

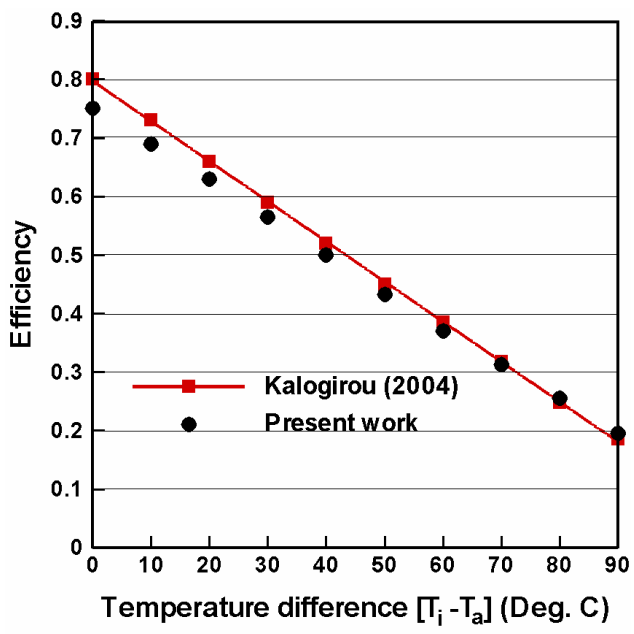

Figure 3: Code validation of heat transfer rate

The current numerical result is compared for collector efficiency - temperature difference $\left[T_{i}-T_{a}\right]$ profile of water with the graphical representation of Kalogirou (2004) of flat plate solar thermal collector. $T_{i}$ and $T_{a}$ are temperatures of input fluid and ambient air respectively. The computation is done taking heat transfer medium as water with irradiation level $1000 \mathrm{~W} / \mathrm{m}^{2}$ and the mass flow rate per unit area $0.015 \mathrm{~kg} / \mathrm{s}$. A survey report on various types of solar thermal collectors and applications was presented by Kalogirou (2004). He presented that generally the collector efficiency linearly depended on temperature difference for a FPSC. Figure 3 demonstrates the above stated comparison. The present numerical solution may be treated as a particular case of general concept of Kalogirou (2004). Percentage of error lies between 2\%-6\%.

\section{Results and Discussion}

In this section, the behavior of $\mathrm{Cu} /$ water nanofluid for different values of variable thermal conductivity $(\gamma)$ and viscosity $(\varepsilon)$ across a riser pipe of a flat plate solar collector are displayed. The considered values of $\gamma$ and $\varepsilon$ are $\gamma(=0,1,2,3$ and 4$)$ and $\varepsilon(=0$, 2, 5, 7 and 10) while the Prandtl number $P r=5.8, I=215 \mathrm{~W} / \mathrm{m}^{2}, T_{a m b}=298 \mathrm{~K}, T_{i n}=300 \mathrm{~K}$, mass flow rate per unit area $m=m^{\prime} / N=$ $0.0037 \mathrm{Kg} / \mathrm{s}, N=7, \phi=2 \%, A=1.8 \mathrm{~m}^{2}, U_{l}=8 \mathrm{~W} / \mathrm{m}^{2} \mathrm{~K}$ and $R e=480$ are kept fixed. The ranges of $\gamma$ and $\varepsilon$ are chosen till significant variation is obtained in the results. The value of $\operatorname{Pr}$ represents water at $300 \mathrm{~K}$. The values of the average Nusselt number, mean bulk temperature, average velocity, percentage of collector efficiency and outlet temperature of working fluid are shown graphically for the pertinent parameters. 


\section{1 Rate of heat transfer}

Figure 4 (i)-(ii) displays the average Nusselt number $(\mathrm{Nu}$ ) of nanofluid and base fluid for the effect of variable thermal conductivity and viscosity respectively. Thermal conduction is the spontaneous transfer of thermal energy through fluid, from a region of high temperature to a region of lower temperature. Mounting thermal conductivity variation parameter $\gamma$ enhances average Nusselt number. From Figure 4(i) it is observed that rate of heat transfer enhances by $18 \%$ and $10 \%$ for nanofluid and base fluid (clear water) with the increasing values of $\gamma$ from 0 to 4 . Thus if it is focused on maximizing the heat transfer coefficient, it is clear that the thermal conductivity of the water-copper nanofluid is the dominant parameter. This is because the thermal conductivity of the solid particles is higher than the clear water (without solid particles). This means that higher heat transfer rate is predicted by the nanofluid than the base fluid $(\phi=0 \%)$.

But from Figure 4(ii) it is seen that mean Nusselt number devalues for the variation of temperature dependent viscosity parameter $\varepsilon$ from 0 to 10 . The rates of heat transfer lessen by $12 \%$ and $20 \%$ for nanofluid and base fluid respectively. The thermal conductivity of nanoparticles is higher than water. That's why decreasing rate of convective heat transfer is found lower for nanofluid than clear water.

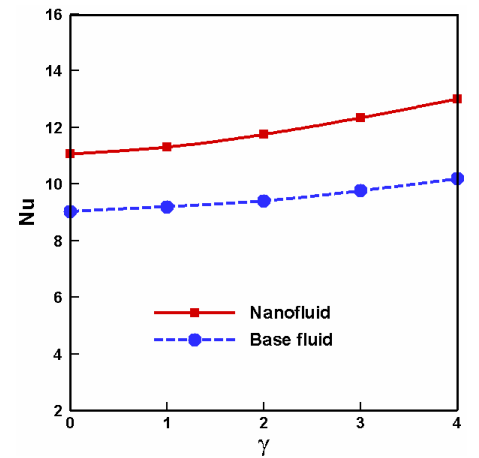

(i)

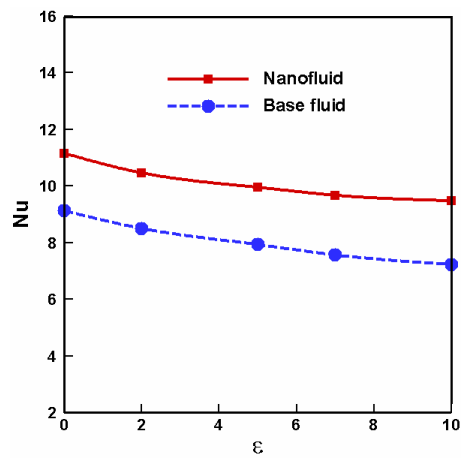

(ii)

Figure 4: Mean Nusselt number for the effect of (i) $\gamma$ at $\varepsilon=2$ and (i) $\varepsilon$ at $\gamma=1$

\section{2 Mean temperature}

The mean temperature $\left(\theta_{a v}\right)$ of both type of fluids inside the riser pipe of a flat plate solar collector for the effect of temperature dependent thermal conductivity and viscosity parameters are displayed by the Figure 5(i)-(ii). From this figure it is found that $\theta_{a v}$ for nanofluid and base fluid grows with the rising of both parameters $\gamma$ and $\varepsilon$. As $\gamma=\delta\left(T_{c o l}-T_{i n}\right)$, so increasing values of $\gamma$ increase this temperature difference between the collector and entering fluid. Then heat is transferred rapidly from top to bottom wall within the working fluids. That's why both velocity and temperature profiles increase with the increasing values of $\gamma$.

On the other hand, for escalating viscosity variation parameter $(\varepsilon)$ the friction among fluid particles rises. As well as mean temperatures of fluids enhance. $\theta_{a v}$ for nanofluid is higher in Figure 5(i)-(ii) with compared to that of base fluid. This is due to the fact that temperature of nanofluid rises for the higher thermal conductivity of copper nanoparticles.

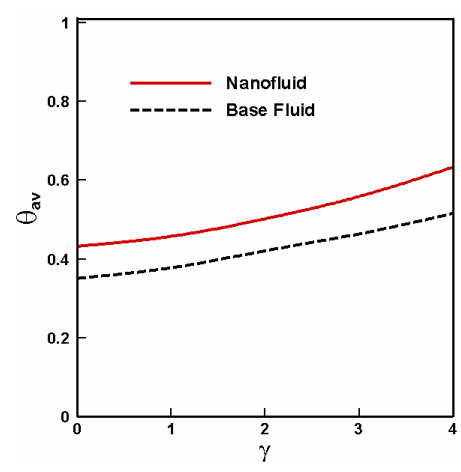

(i)

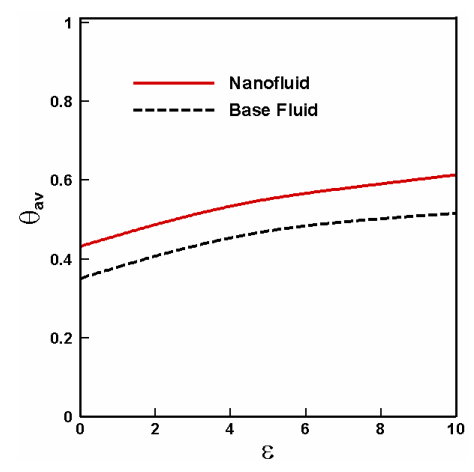

(ii)

Figure 5: Average temperature for the effect of (i) $\gamma$ at $\varepsilon=2$ and (i) $\varepsilon$ at $\gamma=1$

\section{3 Average velocity}

Figure 6(i)-(ii) exposes the average magnitude of velocity $\left(\mathrm{V}_{\mathrm{av}}\right)$ of both nanofluid and clear water inside a fluid passing riser pipe of a flat plate solar collector for the effect of thermal conductivity and viscosity variation respectively. The mean velocity has notable changes with different values of $\gamma$ and $\varepsilon . \mathrm{V}_{\mathrm{av}}$ enhances with increasing and decreasing values of variable thermal conductivity and viscosity respectively. It is well known that movement of highly viscous fluid is slower than low viscous fluid. 
Here base fluid $(\phi=0 \%)$ has higher mean velocity than the water based nanofluid having copper nanoparticles. This is expected because nanofluid that is fluid with solid concentrations does not move freely like clear water.

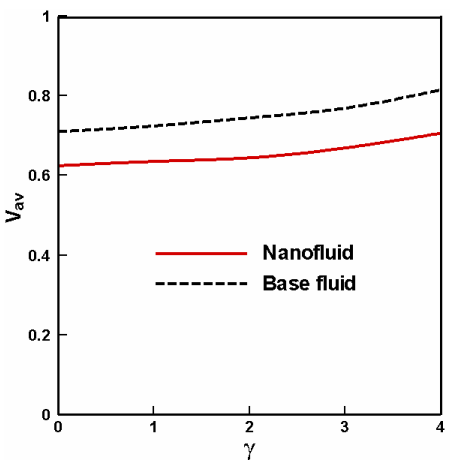

(i)

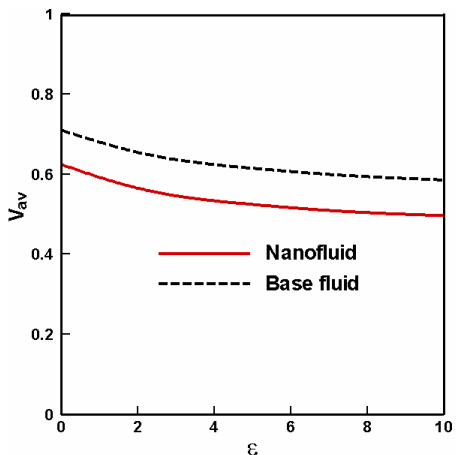

(ii)

Figure 6: Mean velocity for the effect of (i) $\gamma$ at $\varepsilon=2$ and (i) $\varepsilon$ at $\gamma=1$

\subsection{Outlet temperature}

Figure 7(i)-(ii) displays the temperature (dimensional) of water-copper nanofluid at the middle height of the riser pipe with the influences of variable thermal conductivity and viscosity for nanofluid as well as base fluid. From the Figure 7(i) it is shown that the inlet temperature of fluid is maintained at $300 \mathrm{~K}$ and then it increases gradually with the contact of heated solid upper and lower boundaries of the riser pipe. And finally the mean output temperature of nanofluid becomes $313 \mathrm{~K}, 314 \mathrm{~K}, 315 \mathrm{~K}, 316 \mathrm{~K}$ and $317 \mathrm{~K}$ for $\gamma=0,1,2,3$ and 4 respectively.

But mid-height temperature $(T)$ diminishes with growing $\varepsilon$ from 0 to 10 . The mean output temperature of nanofluid becomes $315 \mathrm{~K}, 314 \mathrm{~K}, 313 \mathrm{~K}, 312 \mathrm{~K}$ and $310 \mathrm{~K}$ with the viscosity variation of $\varepsilon=0,2,5,7$ and 10 respectively.

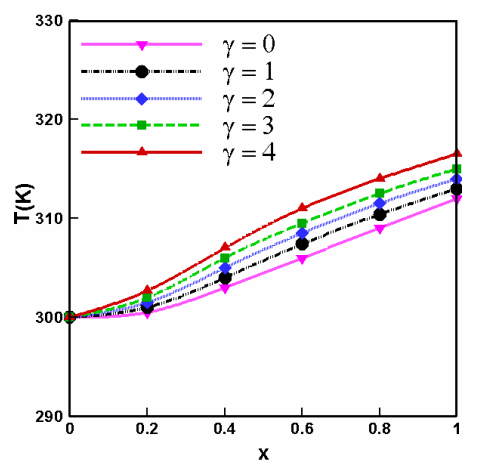

(i)

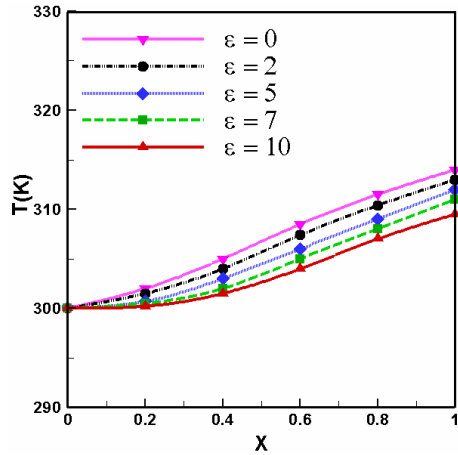

(ii)

Figure 7: Temperature of nanofluid at the middle of riser pipe for the effect of (i) $\gamma$ at $\varepsilon=2$ and (i) $\varepsilon$ at $\gamma=1$

\subsection{Collector efficiency}

The variation of percentage of collector efficiency as a function of the variable thermal conductivity and viscosity varies from 0 - 4 and 0 - 10 are exposed in Figure 8(i)-(ii). It is observed from Figure 8(i) that by introducing flow having more thermal conductivity variation $(\gamma=0-4)$ the collector efficiency increases. Collector efficiency rises from $45 \%$ to $59 \%$ and from $37 \%$ to $51 \%$ for the deviation of $\gamma$ from $0-4$ with $\mathrm{Cu} /$ water nanofluid and clear water respectively.

Consequently rising $\varepsilon$ (from $0-10$ ) decreases collector efficiency $\eta(\%)$ for both type of fluids. Percentage of solar collector efficiency $(\eta)$ is higher for water-Cu nanofluid than base fluid. Collector efficiency devalues from 52\% to $35 \%$ and from $44 \%$ to $27 \%$ for increasing values of temperature dependent viscosity parameter of water-Cu nanofluid and clear water respectively.

\subsection{Mean entropy generation}

The variations of average entropy generation $(S)$ against variable thermal conductivity $(\gamma)$ and viscosity $(\varepsilon)$ are displayed in Figure 9 (i)-(ii). The entropy generation increases for rising $\gamma$ and falling $\varepsilon$. The increment of temperature dependent thermal conductivity, in terms of enhancing heat transfer rate, observed in Figure 4(i) is also obtained in terms of increasing entropy production. It is seen that for a fixed value of $\varepsilon=0$, the $S$ enhances slightly as with increasing $\gamma$. The higher thermal conductivity results in a smaller temperature gradient within the riser pipe of the flat plate solar collector, and thus the average entropy generation caused by heat transfer irreversibility increases. 
The average entropy, for all considered values of $\varepsilon$, is higher with $\mathrm{Cu}$-water and lower with water. As described above, under the absence of viscosity variation condition, the flow within the collector has higher velocity and heat transfer is dominated by viscous effect. Therefore, the mean entropy generation $(S)$ contributions of fluid friction irreversibility and heat transfer irreversibility, respectively, are both high, and thus $S$ is also high. However, as the temperature dependent viscosity increases, the flow velocity within the collector decreases and a lower temperature gradient is formed near the top wall surface and in the outlet. As a result, the effects of fluid friction irreversibility and heat transfer irreversibility in prompting mean entropy generation both decrease. Consequently, the $S$ decreases slowly.

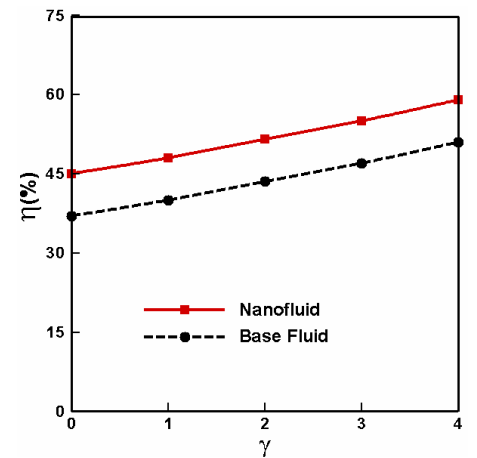

(i)

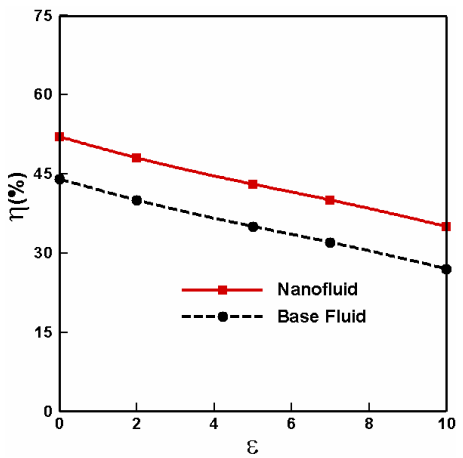

(ii)

Figure 8: Thermal efficiency for the effect of (i) $\gamma$ at $\varepsilon=2$ and (i) $\varepsilon$ at $\gamma=1$

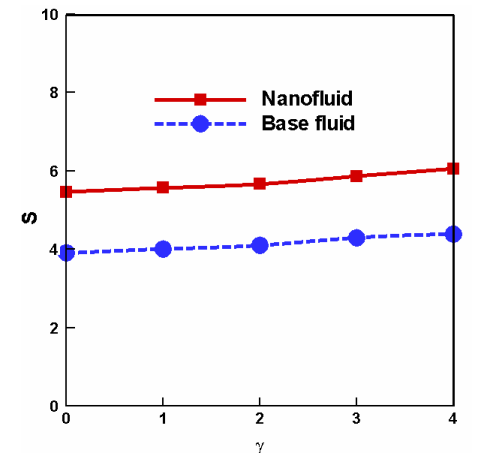

(i)

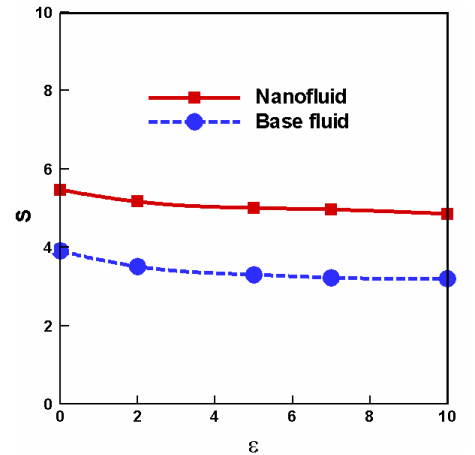

(ii)

Figure 9: Mean entropy generation for the effect of (i) $\gamma$ at $\varepsilon=2$ and (i) $\varepsilon$ at $\gamma=1$

\subsection{Bejan Number}

Figure 10 (i)-(ii) depicts $B e-\gamma$ and $B e-\varepsilon$ profiles for the considered values of $\gamma$ from 0 to 4 and 0 to 10 . Increasing $B e$ is observed for increasing thermal conductivity variation of copper nanoparticles. Finally the Bejan number $(B e)$ approaches unity, the fluid friction irreversibility effect can be ignored.

On the other hand for a particular $\varepsilon$ lower $B e$ is observed for base fluid. Note that the Bejan number is found higher at the constant viscosity of fluids. Then if the viscosity property is variable in terms of temperature the Bejan number reduces.

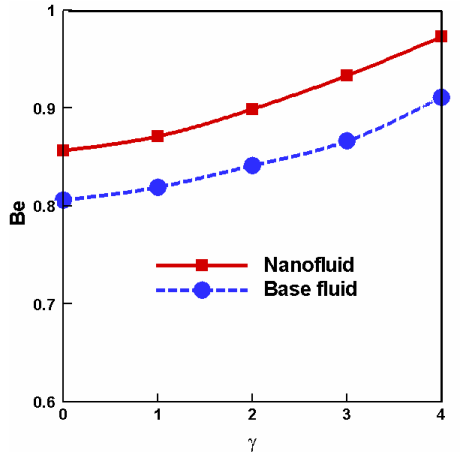

(i)

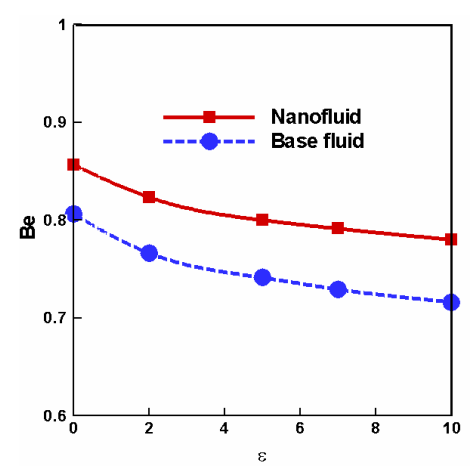

(ii)

Figure 10: Bejan number for the effect of (i) $\gamma$ at $\varepsilon=2$ and (i) $\varepsilon$ at $\gamma=1$ 


\section{Conclusion}

The influences of temperature dependent thermal conductivity and viscosity on assisted convection boundary layer flow through a riser pipe of a flat plate solar collector with water based nanofluid having copper nanoparticles are accounted. Various values of above mentioned variable properties have been considered for the average heat transfer, mean bulk temperature, mean velocity, collector efficiency and outlet temperature of the pipe. For this computation $\operatorname{Pr}, \phi$ and $\operatorname{Re}$ are kept constant as 5.8, 2\% and 480 respectively. The results of the numerical analysis lead to the following conclusions:

- $\quad$ The $\mathrm{Cu}$ nanofluid with the highest $\gamma$ and lowest $\varepsilon$ are established to be more effective in enhancing thermal performance of collector.

- $\quad$ Viscosity variation decreases mean velocity of fluid.

- $\quad$ About $8 \%$ of enhanced thermal efficiency is obtained for thermal conductivity variation.

- $\quad$ To minimize entropy generation thermal conductivity variation is set to be lower.

- Bejan number approaches to 1 for thermal conductivity variation.

\section{Acknowledgement}

The present numerical work is done in the Department of Mathematics, Bangladesh University of Engineering \& Technology. The research is financed by the Research Support \& Publication Division, University Grants Commission, Agargaon, Bangladesh.

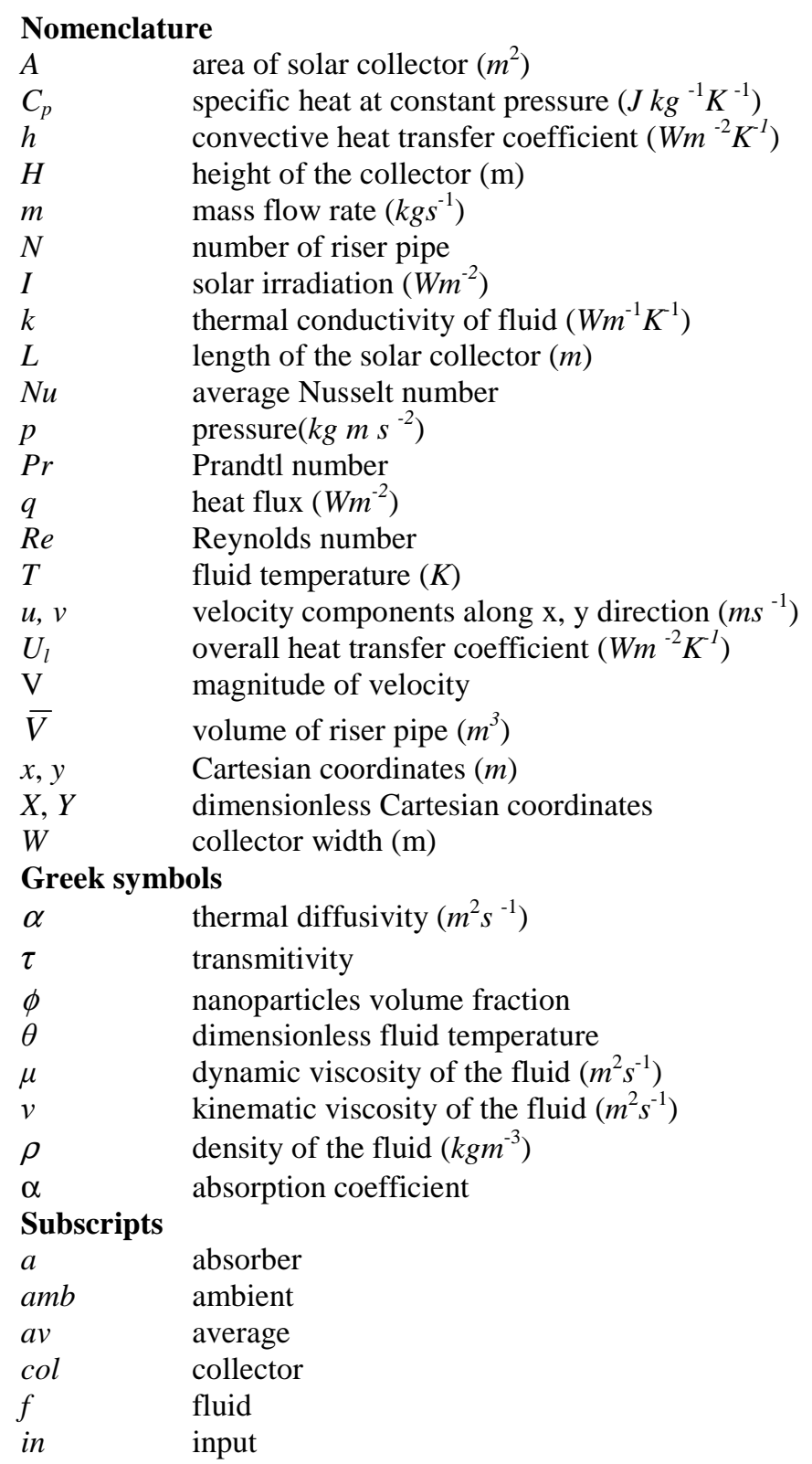




$\begin{array}{ll}\text { loss } & \text { lost } \\ n f & \text { nanofluid } \\ \text { out } & \text { output } \\ \text { recv } & \text { received } \\ s & \text { solid particle } \\ \text { usfl } & \text { useful } \\ \text { Abbreviation } \\ \text { CFD } & \text { computational fluid dynamics } \\ \text { FEA } & \text { finite element analysis } \\ \text { FEM } & \text { finite element method } \\ \text { FPSC } & \text { flat plate solar collector } \\ \text { 2D } & \text { two dimensional }\end{array}$

\section{References}

Abu-Nada, E., 2009. Effects of variable viscosity and thermal conductivity of CuO-water nanofluid on heat transfer enhancement in natural convection: Mathematical Model and Simulation, ASME J. of Heat Transf., Vol. 30, No. 4, pp. 679-690.

Álvarez, A., Muñiz, M.C., Varela, L.M., Cabeza, O., 2010. Finite element modelling of a solar collector, Int. Conf. on Renew. Energies and Power Quality, Granada (Spain).

Amrutkar, S.K., Ghodke, S., Patil, Dr.K.N., 2012. Solar flat plate collector analysis, IOSR J. of Engg., Vol. 2 , No. 2 , pp.07-213.

Bejan, A., 1979. A study of entropy generation in fundamental convective heat transfer. J. of Heat Trans.-Transactions of the ASME, Vol. 101, pp. 718-725.

Bejan, A., 1982. Entropy generation through heat and fluid flow, New York, Wiley.

Bejan, A., 1996. Entropy generation minimization: the method of thermodynamic optimization of finite-size systems and finitetime processes, Boca Raton, CRC Press.

Brinkman, HC, 1952. The viscosity of concentrated suspensions and solution, J. Chem. Phys., Vol. 20, pp. 571-581.

Charraudeau, J., 1975. Influence de gradients de properties physiques en convection force application au cas du tube, Int. J. of Heat and Mass Transf., Vol. 18, pp. 87-95.

Dara, J.E, Ikebudu, K.O., Ubani, N.O., Chinwuko, C.E., Ubachukwu, O.A., 2013. Evaluation of a passive flat-plate solar collector, Int. J. of Advancements in Res. \& Tech., Vol. 2, No. 1.

Dechaumphai, P., 1999. Finite Element Method in Engineering, 2nd ed., Chulalongkorn University Press, Bangkok.

Delavar, M.A., Hedayatpour, M., 2012. Forced convection and entropy generation inside a channel with a heat-generating porous block, Heat Transf.-Asian Res., Vol. 41, No. 7, pp. 580-600.

Duangthongsuk, W. and Wongwises, S., 2009. Measurement of temperature-dependent thermal conductivity and viscosity of $\mathrm{TiO}_{2}$-water nanofluids, Exp. Thermal and Fluid Sci., Vol. 33, No. 4, pp. 706-714.

Elbashbeshy, E.M.A., 2000. Free convection flow with variable viscosity and thermal diffusivity along a vertical plate in the presence of magnetic field, Int. J. Eng. Science, Vol. 38, No. 2, pp. 207-213.

Hooman, K., Ejlali, A., Hooman, F., 2008. Entropy generation analysis of thermally developing forced convection in fluidsaturated porous medium, Appl. Math. Mech.-Engl. Ed., Vol. 29, No. 2, pp. 229-237.

Hossain, MA., Munir, MS., Rees, DAS, 2000. Flow of viscous incompressible fluid with temperature dependent viscosity and thermal conductivity past a permeable wedge with uniform surface heat flux, Int. J. Therm. Sci., Vol. 39, pp. 635-644.

Hwang, Y., Lee, JK., Lee, CH., Jung, YM., Cheong, SI., Lee, CG., Ku, BC., Jang, SP., 2007. Stability and thermal conductivity characteristics of nanofluids, Thermochimica Acta, Vol. 455, No. 1-2, pp. 70-74.

Kalogirou, S.A., 2004, Solar thermal collectors and applications, Progress in Energy and Combustion Science, Vol. 30, pp. 231295.

Karanth, K.V., Manjunath, M.S,. Sharma, N.Y., 2011. Numerical simulation of a solar flat plate collector using discrete transfer radiation model (DTRM)-a CFD approach, Proc. of the World Congress on Engg., III, WCE 2011, London, U.K.

Karuppa, R.R.T., Pavan, P. and Rajeev, D.R., 2012. Experimental investigation of a new solar flat plate collector, Research J. of Engg. Sciences, Vol. 1, No. 4, pp.1-8.

Khorasanizadeh, H., Nikfar, M., Amani, J., 2013. Entropy generation of $\mathrm{Cu}-$ water nanofluid mixed convection in a cavity, Eur. J. Mech. B-Fluid, Vol. 37, pp.143-152.

Li, Y., Xie, H., Yu, W., Li, J., 2011. Investigation on heat transfer performances of nanofluids in solar collector, Materials Sci. Forum, Vol. 694, pp 33-36.

Mahian, O., Kianifar, A., Sahin, A.Z., Wongwises, S., 2014. Entropy generation during $\mathrm{Al}_{2} \mathrm{O}_{3} /$ water nanofluid flow in a solar collector: Effects of tube roughness, nanoparticle size, and different thermophysical models, Int. J. of Heat and Mass Trans., Vol. 78, pp. 64-75.

Martín, R.H., Pinar, A.G., García, J.P., 2011. Experimental heat transfer research in enhanced flat-plate solar collectors, Solar Thermal Applications, World Renew. Energy Congress, pp. 3844-3851. 
Maxwell-Garnett, JC., 1904. Colours in metal glasses and in metallic films, Philos. Trans. Roy. Soc. A, Vol. 203, pp. 385-420.

Molla, MM., Saha, SC. and Hossain, MA., 2012. The effect of temperature dependent viscosity on MHD natural convection flow from an isothermal sphere, J. of Appl. Fluid Mech., Vol. 5, No. 2, pp. 25-31.

Moningi, M.K., Conduction convection radiation processes of a solar collector using FEA, Report 4 pages, University of Massachusetts, Amherst, 2008.

Nasrin, R., Parvin, S. and Alim, M.A., 2014. Entropy generation inside a narrow channel with thermal radiation, Int. J. of Energy \& Tech., Vol. 6, No. 27, pp. 1-9.

Natarajan, E. \& Sathish, R., 2009. Role of nanofluids in solar water heater, Int. J. Adv. Manuf. Techno., DOI 10.1007/s00170008-1876-8, Vol. 45, 5 pages.

Otanicar, T.P., Golden, J.S., 2009. Comparative environmental and economic analysis of conventional and nanofluid solar hot water technologies, Environ. Sci. Techn., Vol. 43, pp. 6082-6087.

Otanicar, T.P., Phelan, P. E., Prasher, R.S., Rosengarten, G. and Taylor, R.A., 2010. Nanofluid-based direct absorption solar collector, J. of Renew. Sust. Energy, Vol. 2, 033102.

Parvin, S., Nasrin, R. and Alim, M.A., 2014. Heat transfer and entropy generation through nanofluid filled direct absorption solar collector, Int. J. of Heat and Mass Trans., Vol. 71, pp. 386-395.

Parvin, S., Nasrin, R., Alim, MA., Hossain, NF. and Chamkha, AJ., 2012. Thermal conductivity variation on natural convection flow of water-alumina nanofluid in an annulus, Int. J. of Heat and Mass Transf., Vol. 55, No. 19-20, pp. 5268-5274.

Piao, Y., Hauptmann, EG., Iqbal, M., 1994. Forced convective heat transfer in cross-corrugated solar air heaters, ASME Journal of Solar Energy Engg., Vol. 116, pp. 212-214.

Polvongsri, S. and Kiatsiriroat, T., 2011. Enhancement of flat-plate solar collector thermal performance with silver nano-fluid, The 2nd TSME Int. Conf. on Mech. Engg., Krabi.

Rahman, M.M., Mamun, A.A., Azim, M.A. and Alim, M.A., 2008. Effects of temperature dependent thermal conductivity on MHD free convection flow along a vertical flat plate with heat conduction, Nonlinear Analysis: Modell. and Cont., Vol. 13, No. 4, pp. 513-524.

Roslan, R., Saleh, H. and Hashim, I., 2011. Buoyuancy driven heat transfer in a naonofluid filled trapezoidal enclosure with variable thermal conductivity and viscosity, Num. Heat Transf., Part A: Applications, Vol. 60, No. 10, pp. 867-882.

Sandhu, G., 2013. Experimental study of temperature field in flat-plate collector and heat transfer enhancement with the use of insert devices, M. of Engg. Sci. theseis, The School of Graduate and Postdoctoral Studies, The University of Western Ontario London, Ontario, Canada.

Shahi, M., Mahmoudi, AH., Raouf, AH., 2011. Entropy generation due to natural convection cooling of a nanofluid. Int. Commun. in Heat and Mass Transf., Vol. 38, pp. 972-983.

Struckmann, F., 2008. Analysis of a flat-plate solar collector, Project Report MVK160 Heat and Mass Transport, Lund, Sweden.

Taylor, C., Hood, P., 1973. A numerical solution of the Navier-Stokes equations using finite element technique, Computer and Fluids, Vol. 1, pp. 73-89.

Taylor, R. A., Phelan, P. E., Otanicar, T.P., Walker, C.A., Nguyen, M., 2011. Applicability of nanofluids in high flux solar collectors, J. of Renew. Sust. Energy, Vol. 3, 023104.

Tripanagnostopoulos, Y., Souliotis, M., Nousia, T., 2000. Solar collectors with colored absorbers, Solar Energy, Vol. 68, pp.343356.

Zambolin, E., 2011. Theoretical and experimental study of solar thermal collector systems and components, Scuola di Dottorato di Ricerca in Ingegneria Industriale, Indirizzo Fisica Tecnica.

Zienkiewicz, O.C., and Taylor, R.L., 1991. The finite element method, Fourth Ed., McGraw-Hill.

\section{Biographical notes}

Rehena Nasrin received M. Sc. and M. Phil. from University of Dhaka and Bangladesh University of Engineering and Technology, Bangladesh in 2002 and 2009 , respectively. Now she is Assistant Professor in the Department of Mathematics, Bangladesh University of Engineering and Technology, Bangladesh.

M. A. Alim received M. Phil. and Ph. D. from Bangladesh University of Engineering and Technology, Bangladesh and Loughborough University, Loughborough, Leicestershire, UK respectively. Now he is Associate Professor in the Department of Mathematics, Bangladesh University of Engineering and Technology, Bangladesh. He published more than hundred papers in various international journals in the field of Computational Fluid Dynamics. He is reviewer of more than twenty five international journals.

Received June 2014

Accepted May 2015

Final acceptance in revised form June 2015 